 \\ Revista Vol. 24(47) \\ Prolegómenos enero-junio - ISSN: 0121-182x - e-ISSN: 1909-7727 - pp. 79-98
}

DOI: https://doi.org/10.18359/prole.4865

\title{
Análisis histórico de la responsabilidad civil de la actividad bancaria y su impacto en Colombia*
}

\author{
Jorge Armando Corredor Higuera ${ }^{\mathrm{a}}$ - Daniela Ríos Moreno ${ }^{\mathrm{b}}$
}

\begin{abstract}
Resumen: el objetivo de este trabajo es realizar un análisis histórico de la evolución de la actividad bancaria desde la época mesopotámica hasta los esquemas digitales actuales, haciendo hincapié en la institución de la responsabilidad civil por la actividad bancaria. El presente texto pretende, en primer lugar, identificar los diferentes ámbitos de la responsabilidad civil bancaria, por lo que se aborda su origen y desarrollo. En segundo lugar, estudiar el impacto de la culpa en el régimen de responsabilidad por la actividad financiera. Posteriormente, se realiza algunas consideraciones relacionadas con los últimos avances legales y jurisprudenciales sobre un régimen objetivo de responsabilidad civil bancaria. La metodología de investigación consistió en el análisis de fuentes bibliográficas e información pública. Es de tipo descriptivo y enfoque cualitativo; tiene el propósito de explicar las características del tema tratado a partir del análisis de las fuentes de información.
\end{abstract}

Palabras clave: actividad bancaria; actividad profesional; culpa; responsabilidad civil; responsabilidad objetiva

Recibido: 28 de mayo de 2020

Aceptado: 10 de febrero de 2021

Disponible en línea: 06 de agosto de 2021

Cómo citar: Corredor Higuera, J. A., \& Ríos Moreno, D. (2021). Análisis histórico de la responsabilidad civil de la actividad bancaria y su impacto en Colombia. Prolegómenos, 24(47), 79-98. https://doi.org/10.18359/prole.4865

* Artículo de investigación, parte de la investigación desarrollada por el Observatorio de Derecho Financiero y del Mercado de Valores, de la Universidad Externado de Colombia, grupo de categoría C de Colciencias.

a Abogado y especialista en Derecho Privado, de la Universidad Nacional de Colombia, LL. M. en Derecho Internacional, Inversiones, Comercio y Arbitraje, impartido por la Universidad de Heidelberg (DAAD) y doctorando de la Universidad Carlos III de Madrid. Universidad Externado de Colombia, Bogotá, Colombia.

Correo electrónico: jorge.corredor@uexternado.edu.co ORCID: https://orcid.org/0000-0003-4672-1789

b Abogada y especialista en Derecho Administrativo de la Universidad Nacional de Colombia. Universidad Externado de Colombia, Bogotá, Colombia.

Correo electrónico: daniela.rios@uexternado.edu.co ORCID: https://orcid.org/0000-0001-5502-0090 


\title{
Historical Analysis of the Civil Liability of Banking Activity and its Impact on Colombia
}

\begin{abstract}
: the purpose of this paper is to carry out a historical analysis of the development of banking activity from Mesopotamian times to the current digital schemes, emphasizing the institution of civil liability for banking activity. First of all, the present text aims to identify the different areas of bank civil liability, for this reason its origin and development will be addressed. Second, it is studied the impact of fault on the liability regime for financial activity. Subsequently, some considerations related to the latest legal and jurisprudential advances on an objective regime of bank civil liability will be made. The research methodology consisted of the analysis of bibliographic sources and public information. It is of a descriptive type and qualitative approach; it has the purpose of explaining the characteristics of the subject dealt with based on the analysis of the sources of information.
\end{abstract}

Keywords: banking activity; civil liability; fault; professional activity; strict liability

\section{Análise histórica da responsabilidade civil da atividade bancária e seu impacto na Colômbia}

Resumo: o objetivo deste trabalho é realizar uma análise histórica da evolução da atividade bancária desde a época mesopotâmica até os esquemas digitais atuais, enfatizando a instituição da responsabilidade civil pela atividade bancária. Neste texto, pretende-se, em primeiro lugar, identificar os diferentes âmbitos da responsabilidade civil bancária, portanto se abordam sua origem e desenvolvimento. Em segundo lugar, estudar o impacto da culpa no regime de responsabilidade pela atividade financeira. Em seguida, são apresentadas algumas considerações relacionadas com os últimos avanços legais e jurisprudenciais sobre um regime objetivo de responsabilidade civil bancária. A metodologia de pesquisa consiste na análise de fontes bibliográficas e informações públicas. É de tipo descritivo e abordagem qualitativa, com o objetivo de explicar as características do tema tratado a partir da análise das fontes de informação.

Palavras-chave: atividade bancária; responsabilidade civil; culpa; atividade profissional; responsabilidade objetiva 


\section{Introducción}

Desde sus orígenes, la actividad bancaria ha cumplido un papel trascendental en el desarrollo social como mecanismo de asignación de recursos. Dentro del desarrollo del negocio bancario ha evolucionado una serie de operaciones de captación de recursos, operaciones de crédito, sistemas de pago y administración de recursos, las cuales, se han adaptado y desarrollado en cada modelo económico y de producción, verbigracia, desde el trueque hasta llegar al sistema capitalista vigente.

En la actualidad, los mercados financieros cuentan con un desarrollo sin precedentes, mediado por el impacto de los mercados transfronterizos, los avances tecnológicos en materia financiera y la aparición de consumidores digitales. De esta manera, se evolucionó de los simples contratos realizados en arcilla y papiro a operaciones digitales financieras en tiempo real, de tipo local o internacional, donde existen criterios tecnológicos en materia de seguridad y acceso a los recursos.

En este contexto, el sistema de responsabilidad frente a las operaciones bancarias ha tenido una evolución que responde al desarrollo de la institución de la responsabilidad civil. En otras palabras, a lo largo de la historia, el régimen de responsabilidad de la actividad bancaria respondió, y responde aún, a dinámicas económicas, sociales y tecnológicas que determinan su estructuración.

Bajo estos supuestos, este trabajo, primero, analiza la evolución del régimen de responsabilidad civil de la actividad bancaria y, segundo, explica cómo se estructura hoy en un esquema objetivado de responsabilidad por razón de los desarrollos tecnológicos. Como objetivos específicos, se busca: (1) identificar los diferentes estadios de la responsabilidad civil bancaria; (2) mostrar el impacto de la culpa en el régimen de responsabilidad de la actividad financiera; y (3) establecer los últimos avances legales y jurisprudenciales para evidenciar la problemática que representa la ausencia de un régimen objetivo de la responsabilidad de las entidades financieras. Lo que permitirá defender la hipótesis de que, en Colombia, se requiere un sistema de responsabilidad especial, de carácter objetivo, que resulte más favorable para el consumidor financiero.

El método de investigación utilizado es de tipo cualitativo, con una metodología de análisis histórico, a partir del análisis de fuentes bibliográficas e información de carácter público, consultadas en bases de datos científicas en materia jurídica. Se hace la salvedad de que, por la complejidad del asunto y la delimitación del tema, varias de las instituciones mencionadas se analizan someramente, sin que esto signifique que no cuentan con la importancia del caso.

Para el desarrollo de este artículo, se analizó la evolución de la actividad bancaria, haciendo algunas reflexiones sobre el régimen de responsabilidad en Mesopotamia, Grecia, Roma, la Edad Media, los procesos de codificación y la Revolución Industrial. Por último, se dan a conocer los retos en materia de responsabilidad de las entidades financieras en la era tecnológica.

\section{Antecedentes en Mesopotamia, Babilonia y Grecia}

Dentro del desarrollo comercial de Babilonia, ya existían algunas instituciones bancarias en el siglo vi a. C. El proceso de los bancos en la época, como describe Gustave Nöel mencionando al Banco de Egibes e Hijos, consistía en recibir dinero en custodia y competir con los templos por el otorgamiento de créditos a particulares (Villamarín-Gutiérrez, 1972, p. 3). Así, la actividad bancaria fue extendiéndose hasta dar origen a otras entidades, como la banca Eanasir y la banca Neboahiddin, en Babilonia; cuyas operaciones consistían en efectuar pagos por cuentas, custodiar depósitos e, incluso, cumplir funciones notariales. De esta manera, surgió la idea de formalizar el consentimiento, a través de una firma sobre una tablilla con el objetivo de "garantizar el pago del precio de una adquisición inmobiliaria y obligarse personalmente a indemnizar al vendedor en caso de fallecimiento del comprador" (Duarte-French, 1959, p. 29).

Esto llevó a la materialización de una especie de responsabilidad, sin que existiera una conducta negligente imputable a las partes. Motivo por 
el cual, cuando se presentaban hechos que generaban un desequilibro en la relación contractual, ajenos a la conducta de las partes, se imponía la obligación de indemnizar a la parte contractual, sobre la que recaía el perjuicio (Duarte-French, 1959, p. 29).

El Código de Hammurabi contemplaba una tasa de interés para los préstamos de cebada y de dinero ${ }^{1}$. Asimismo, la usura era considerada una vulneración a la ética y las buenas costumbres (Fernández-Arias et al., 2000, p. 386). Debe señalarse que, Babilonia fue especialmente sensible frente a la percepción de intereses ${ }^{2}$, pues se establecieron sanciones en el supuesto de no cumplir con los límites citados ${ }^{3}$.

Según Keister (1963), en la dinastía de Ur, al sur de Mesopotamia, la economía seguía siendo premonetaria, por tanto, las operaciones eran realizadas en especie. Allí, las principales actividades bancarias eran el depósito y préstamo de mercancías, y los templos asumían la responsabilidad por la custodia y restitución de los objetos depositados. Así, mientras el depósito era gratuito, el préstamo generaba un interés corriente (sibtou), dependiendo de si la mercancía era cereal - $33 \%$ de interés - o determinados metales - 20\% de interés-(Pérez-Ramírez, 2009, p. 23).

1 Si un mercader presta cebada o dinero con interés, se quedará con un interés de 100 silas por cada kur; si lo que presta es dinero, se quedará con un interés $1 / 6$ de siclo y 6 granos por cada siclo de plata" (Código de Hammurabi).

2 Sin embargo, estaba prevista una excepción frente a las sanciones tradicionales en contra de la búsqueda de los rendimientos que se producen cuando las ganancias están encaminadas en favor de otra persona, sobre todo, para instituciones consideradas santas por la comunidad, y con el objetivo de desarrollar actividades socialmente necesarias (Jursa, 2002).

3 "Si un mercader hace un préstamo de cebada o dinero que genera intereses y [...] entrega el dinero según una pesa pequeña o la cebada según un celemín pequeño, pero luego, cuando cobra, cobra el dinero según una pesa grande o la cebada según un celemín grande, perderá todo lo que haya prestado" (Código de Hammurabi, § 74).
En este contexto, los campesinos realizaban sus depósitos de cosechas y otros bienes cuantiosos a los reyes y sacerdotes para que estos los custodiaran, frente a posibles riesgos. Esta práctica comercial se materializó en ciudades antiguas como Mesopotamia y Babilonia (Universidad Nacional Autónoma de México -Unam, s.f.).

A grandes rasgos, el Código Hammurabi determinaba la existencia de una solemnidad para la celebración del contrato de depósito al señalar: "Si un hombre da a otro hombre en depósito plata, oro o lo que sea, que todo lo que entrega lo ensene a testigos, que redacte un contrato y que luego haga la entrega" (Código de Hammurabi, $\$ 122$ ). De la citada disposición, empezó a establecerse un perfeccionamiento y una solemnidad para la celebración de contratos, a través de la presencia de testigos y la obligación del depositario de entregar los bienes dados en depósito. Además, el mismo código sancionaba el incumplimiento de la solemnidad, al consagrar el cierre de la vía judicial para la reclamación de los bienes dados en depósito: " $\mathrm{Si}$ efectúa la entrega sin testigos ni contrato y luego se lo niegan en el lugar en que lo entregó, en ese caso no podrá haber reclamación judicial" (Código de Hammurabi, \$123).

En la hipótesis en la cual el contrato se perfeccionara y existiera incumplimiento en la restitución de los bienes, se generaba como sanción el pago del duplo. Así pues, el párrafo 124 determina: "Si un hombre da a otro hombre en custodia plata, oro o lo que sea ante testigos y luego él se lo niega, y se comprueba lo debido a ese hombre, y pagará dos veces todo lo que niega" (Código de Hammurabi, $\$ 124)$.

De igual manera, en el Código Hammurabi se consideraba delito público cualquier incumplimiento de la solemnidad contractual del depósito, cuya pena era la ejecución bajo el siguiente supuesto: "Si un hombre compra o recibe en depósito plata u oro o un esclavo o esclava o un buey, o una oveja, o un asno, o lo que sea, de manos de un hijo de un hombre o del esclavo de un hombre sin testigos ni contrato, ese hombre es un ladrón; será ejecutado" (Código de Hammurabi, $\$ 7$ ).

En términos prácticos, con respecto a las operaciones de préstamo, el código traía consigo una 
serie supuestos de hecho, en los cuales se determinaban tanto sanciones de tipo privado como de tipo público en caso de incumplimiento de las obligaciones del acreedor o el deudor. En lo que actualmente se asimilaría a un contrato de mutuo con interés, el Código de Hammurabi señala:

Si un mercader presta cebada o dinero con interés, se quedará con un interés de 100 silas por cada kur; si lo que presta es dinero, se quedará con un interés $1 / 6$ de siclo y 6 granos por cada siclo de plata. $(\$ 70)$

Igualmente, se consagra una sanción del duplo en el supuesto de incumplimiento del mercader:

Si un mercader [...] recibe [...] con interés [...] y luego no descuenta los pagos ya cobrados en cebada o dinero, o no extiende otra tablilla, o suma el interés al capital, ese mercader devolverá por partida doble la cebada [o el dinero] cobrada. ${ }^{4}$ (Código de Hammurabi, $₫ 73$ )

En sentido similar, se establecía una sanción de carácter público de ejecución frente al mercader en cuanto a sus obligaciones, cuando el citado código estipuló que

si [un mercader] efectúa un préstamo [...], perderá todo lo que haya prestado. Si un hombre toma prestados cebada o dinero de un mercader y luego no tiene ni cebada ni dinero para devolver, pero tiene otros objetos propios, que le entregue a su mercader lo que tenga a mano, en presencia de testigos, según lo que valga: que el mercader no se oponga, que lo acepte. (Código de Hammurabi, \$ 75)

Por otra parte, en la antigua Grecia, los templos y los palacios desarrollaron las primeras actividades de comercio de dinero (Pérez-Ramírez, 2009 , p. 26), por lo que son los primeros bancos en los cuales se depositaba todo tipo de valores para

4 De igual manera, frente al incumplimiento del deudor, se hace alusión a disposiciones de las leyes del Rey en los siguientes términos: "Si un hombre que tiene una deuda no tiene el dinero para devolver, que se quede con cebada o dinero según la ley del Rey, siendo su interés anual de una fanega por cada kur; si el mercader aumenta el interés [por la cebada a 100 silas] por kur [o a más de] de siclo y seis granos [por siclo de plata] y se queda con ello, perderá lo que haya prestado” (§ 71). salvaguardarlos. Posteriormente, conforme con la evolución y las dinámicas de las polis y actividades comerciales, los bancos pasaron a manos privadas (Gallo , 2013, p. 55), como es el caso del banquero

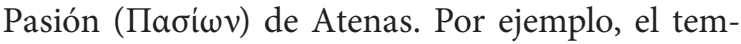
plo de Delfos recibía grandes sumas de valores, representadas en metales preciosos y registraba un ingreso por intereses del $10 \%$, derivado de los préstamos (Villamarín-Gutierrez, 1972, p. 4).

En Grecia existían banqueros privados, dedica-

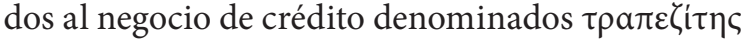
(trapezitas) que cumplían el innoble oficio de cambistas (López-López, 2003, p. 42). Estas personas operaban en ciudades portuarias con actividades de cambio, efectuaban pagos y recibían depósitos en dinero para entregarlo a título de depósito a terceros (Unam, s.f.). También los кo $\lambda \lambda \nu \beta \iota \sigma \tau \eta \dot{~}$ (kolibistas) cumplían esta función y celebraban el depósito en cuentas y préstamos junto a los templos (Morles-Hernández, 2007, p. 610).

Otro punto que atañe a sus actividades es la sistematización de los registros contables en libros. Esta práctica tenía amplio alcance probatorio ante la justicia, cuando se presentaban controversias frente a la responsabilidad de quienes ejecutaban operaciones financieras y custodiaban bienes. Igualmente, se evidencia el destierro a modo sanción y la destitución para quienes manejaban indebidamente la banca y los recursos, como sucedió en el caso particular de Hicesio y Diógenes, quienes dirigían el banco de Sinope y fueron acusados de emitir una falsa moneda (Pérez-Ramírez, 2009, p. 26), lo que generó un incremento en el costo de vida de la población

\section{La banca en Roma y su sistema de responsabilidad}

En Roma, entregar los recursos a título de depósito era considerado una actividad de interés público: "Ulpiano menciona la fides publica en D 42.5.24.2, Gayo dice en D 2.13.10.1 que la actividad de los argentarii tiene una estrecha relación con la vida pública, y Papiano en D 16.3.8 afirma que su trabajo era indispensable para los negocios" (MurilloVillar, 2014, p. 2). 
Es importante tener en cuenta que, en Roma, existían diferentes tipos de banqueros, a saber: los banqueros privados (argentarius) y los banqueros públicos (mansarius, nummularius, trapezita y argentarius coactor) (Murillo-Villar, 2014, p. 1). En este sentido, los banqueros argentarius, nummularius, coactor argentarius, mensarius, mensularius y trapezita eran considerados los banqueros en Roma hacia finales del siglo Iv a. C. Los nummularii y coactores argentarii ejercían sus facultades desde finales de la República y se desempeñaban como cambistas, ensayadores de monedas e intermediarios en subastas (García-Ludeña, 2015, p. 780).

Entretanto, los trapezitas provienen originalmente de Grecia y se desempeñaban como cambistas de moneda. Algunos historiadores manifiestan que en el siglo vir a. C. los trapezitas tomaron gran importancia, Savranky (1986) los describe como "sujetos que colocaban sus mesas de forma trapezoidal (de ahí su nombre) en las que realizaban operaciones de cambio de las monedas que estaban en circulación" (p. 13).

En sentido similar, los nummularii eran banqueros públicos, que se dedicaban a la labor de cambistas, realizando los trámites pertinentes para que los bienes en especie fueran cambiados por metales. Adicionalmente, intercambiaban metales de mayor valor por otros de menor valor $y$ verificaban su autenticidad (Soriano-Cienfuegos, 2010, p. 329). Siguiendo a Esmonde Cleary (2000, p. 73), estos banqueros compraban oro y plata a cambio de bronce.

En cuanto a los mensarii, eran banqueros públicos que ejercían funciones de prestamistas de dinero a los deudores. De ese modo generaban seguridad al Estado. Al respecto, según Leonhard Schmitz (1875) de la High School of Edinburgh,

fueron nombrados en el 352 a. C., en el momento en que los plebeyos estaban tan profundamente involucrados en la deuda, que se vieron obligados a pedir prestado dinero a los nuevos acreedores para pagar a los antiguos, y así se arruinaron por completo [...]. Dichos banqueros fueron nombrados en Roma en varias ocasiones y siempre que las deudas pesaban mucho sobre la gente. (p. 750; traducción propia)
Por otro lado, los argentarii eran banqueros privados que empezaron como cambistas de moneda y se desempeñaron realizando negocios bajo su propia responsabilidad, por ejemplo, subastas con sus clientes. Así, creaban mercados y, adicionalmente, recibían cartas de crédito para garantizar los pagos de los clientes (del Granado, 2009, p. 186) ${ }^{5}$.

En este punto es necesario traer a colación los principales referentes legales sobre la materia en el Derecho Romano. Lo primero es que, en los desarrollos legales, la ley de las Doce Tablas diferenció el régimen de responsabilidad frente al depósito y la operación de crédito. En cuanto a la responsabilidad en materia de depósitos, la citada ley consagró un solo artículo sobre el particular: "Si el depositario extraviase o causase algún perjuicio dolosamente a la cosa que tiene en depósito, quedará sujeto a la pena de duplo" (Quisbert, 2006, p. 8). Del postulado, puede observarse el carácter de la

5 Schmitz (2020) amplía en detalle algunas actividades mercantiles de estos banqueros: (1) "Permutatio o el intercambio de moneda extranjera por moneda romana. En épocas posteriores, cuando los romanos se familiarizaron con la costumbre griega de usar letras de cambio, los argentarii romanos, por ejemplo, recibieron sumas de dinero que tuvieron que pagar en Atenas, y luego sacaron una cuenta pagable en Atenas por algún banquero de esa ciudad. Este modo de realizar transacciones comerciales también se llama permutatio". (2) "El mantenimiento de sumas de dinero para otras personas. El propietario puede depositar dicho dinero y realizar pagos, y en este caso se llamaba depósito [...]. El argentarius, por tanto, hizo casi el mismo tipo de negocio que un banquero moderno. Muchas personas les confiaron todo su capital"; (3) "Su conexión con el comercio y las subastas públicas. Esta rama de su negocio parece haber sido una de las más antiguas. En las ventas y compras privadas, actuaban como agentes [...], a veces se comprometieron a vender todo el patrimonio de una persona [...]. En las subastas públicas estuvieron casi siempre presentes, registrando los artículos vendidos, sus precios y compradores, y recibiendo el pago de los compradores [...]. Sin embargo, en las subastas, los argentarii podían realizar transacciones comerciales a través de sus empleados o sirvientes, a quienes se les llamó coactores por cobrar el dinero" (pp. 130-132). 
sanción, donde se determina el sistema de duplicidad como medio de pena en caso de incumplimiento por parte del depositario.

En el caso del préstamo, frente al acreedor, se establecía que si exigía a otro más usura que el $12 \%$ anual, quedaría sujeto a la pena del duplo (Tabla III, No. 2). En este orden de ideas, el régimen frente a los deudores era bastante estricto, en el cual se establecía una serie de estadios en cuanto al incumplimiento de la obligación: (1) el reconocimiento de la deuda ante el tribunal al cual debía acudir; (2) el plazo de treinta días para pagar la obligación; (3) la aprehensión del deudor y su comparecencia ante el tribunal por el no pago de la obligación; (4) si no se pagaba la obligación, el acreedor se podía llevar consigo preso al deudor, atado a una correa o con cadenas de quince libras de peso; (5) dentro del término de sesenta días preso, sin que hubiera pago o acuerdo de pago, el deudor era llevado ante el pretor, donde se le recordaba la existencia de la obligación; (6) vencidos los sesenta días sin pago, el deudor era vendido como esclavo o condenado a muerte, y su cuerpo repartido entre los acreedores ${ }^{6}$ (Marcos-Celestino, 2000, p. 364).

6 "El deudor que no hubiere podido responder a sus compromisos debía reconocer su deuda ante el tribunal (art. 1-5, I). En el caso de que esta comparecencia ante los tribunales no finalizase en el mismo día, el demandante presentaría fiadores (vades et subvades) que garantizarían su presencia de nuevo al día siguiente. El procedimiento de la legis actio (la actuación legal) que cita al demandado ante los tribunales recibe el nombre de in ius vocatio [...]. El gesto que las Doce Tablas registran para manifestar el requerimiento de una persona ante los tribunales era echarle la mano encima (art. 2, I: manum endo iacito); además de esta forma de vocatio in ius, otro recurso primitivo de requerimiento judicial era el mojarle con saliva la oreja al demandado, gesto con el que se ponía de manifiesto públicamente que se le demandaba. Tras su comparecencia ante los tribunales, al deudor se le concedían treinta días de plazo para satisfacer la deuda (art. 1, III). Si, pasado ese plazo, la deuda no se había satisfecho, la legis actio seguía su curso: el deudor era aprehendido y llevado ante el magistrado (art. 2, III); si en ese momento el reo no cumplía la sentencia y nadie salía fiador legal de su deuda, al deman-
En el 342 a. C., se promulgó la Lex Genucia, por medio de la cual se prohibió el cobro de intereses en los préstamos, de modo que el pago y el cobro de intereses se convirtió en delito público. No se conocen las consecuencias de la citada ley, ni si realmente fue derogada (Andreu, 1999, p. 91). En el 89 a. C., el pretor A. Sempronius Asellio, con fundamento en una ley en desuso (no se tiene claridad si fue la Lex Genucia), prohibió el pago de intereses debido a una crisis en el pago de la deuda. No se tiene claridad si con la Lex Marcia o la Lex Junia de Federatione se autorizó nuevamente el cobro de intereses, entre 200 y 170 a. C. (Andreu, 1999). Finalmente, a través de la Lex Onciarum Foenus se fijó un interés máximo del $12 \%$ anual para los préstamos (Unam, s.f.).

Dentro del Corpus Iuris Civilis puede encontrarse una nutrida variedad tanto de operaciones bancarias, como de sistemas de responsabilidad de dicha actividad en Roma. En efecto, sobre los sistemas de responsabilidad, desde aquel entonces se consideraba que dichas operaciones bancarias estaban respaldadas por la confianza que otorgaban los clientes a las instituciones. De allí que, los argentarii tuvieran una estrecha relación con la vida pública, lo que les facilitaba hacer negocios propios de la actividad financiera romana (Murillo-Villar,

dante se lo podrá llevar consigo atado con una correa o con cadenas de quince libras de peso. En este punto el art. 3, III hace hincapié en el peso de las cadenas, que nunca debería ser inferior a las quince libras [...]. Si el reo tiene con qué vivir, deberá mantenerse a sus expensas; de lo contrario, el acreedor que lo tiene preso habrá de darle una libra de trigo al día [...]. El art. 5, III alude a una posibilidad legal de llegar aún a compromisos; en caso contrario, los deudores eran mantenidos en prisión durante sesenta días [...]. La Tabla III se cierra con el castigo que se imponía al acreedor al cabo de los sesenta días: si la deuda seguía sin ser satisfecha, podía ser vendido como esclavo o condenado a muerte, pudiéndose hacerlo trozos para repartirlo entre los acreedores (art. 6, III). Sin embargo, Aulo Gelio comenta que no tiene noticias de que medida tan bárbara hubiera sido nunca llevada a la práctica” (Marcos-Celestino, 2000, p. 364). 
2014, p. 2), por ejemplo, conservar el dinero de las personas bajo la modalidad de depósito bancario.

Asimismo, el banquero era responsable (in solidum) por los daños generados a los clientes como consecuencia de no brindarles la información adecuada, suficiente y verás, o por cambiar las condiciones de los contratos, lo que equivale a vulnerar sus deberes de información (Salazar-Revuelta, 2013, p. 98).

Ahora bien, existió un régimen de responsabilidad especial para el banquero declarado insolvente según el tipo de cliente. En consecuencia, el Digesto contempla una especie de categorías de clientes:

Se había venido formando, al menos para la hipótesis de quiebra de un banco, un régimen jurídico diferenciado según la categoría de clientes, que podríamos definir "los ahorradores", merecedores de una protección especial, y para aquella de los "especuladores", que estaban llamados a soportar el riesgo de una crisis bancaria del mismo modo que todos los otros acreedores no privilegiados (Cerami, 2017, p. 282)

Igualmente, se observa que la responsabilidad de los banqueros por insolvencia no se limitaba únicamente al ámbito pecuniario, sino también al disciplinario, como lo relacionado con la prohibición de acceder a cargos públicos o cumplir funciones de banquero ${ }^{7}$.

Con respecto a las actividades bancarias se desarrollaban principalmente a través de las siguientes operaciones (Petrucci, 2010):

1. Mutuos con dinero de los clientes. Bajo esta modalidad, si en el contrato figuraba alguna hipoteca, el banquero tenía la facultad de adjudicarse bienes cuando el capital no fuera restituido (Petrucci, 2010, p. 352).

7 En Roma, el banquero quebrado "no solo respondía con todo su patrimonio para satisfacer el pago a sus acreedores”, sino que “como había sido condenado como consecuencia del ejercicio de la actio depositi, acción infamante que no solamente conllevaba un gran desprestigio social y la imposibilidad de acceder a cargos públicos”, es probable que "no volviera a ejercer la profesión de banquero, pues había defraudado grandemente la confianza de sus ciudadanos" (Murillo-Villar, 2014, p. 10).
2. Mutuos documentados de dinero con presunción de onerosidad. En el contrato mutuum, caracterizado por ser unilateral y gratuito, el mutuante no recibía ningún beneficio por el préstamo de ese capital. Desde entonces, surgió en Roma la idea de estipular intereses sobre el capital dado en mutuo, denominados usurae. Estos intereses solo podían ser acordados y reclamados mediante una estipulación especial denominada stipulatio usurarum (Argüello, 1998, p. 311).

3. Venta de forma no escrita de cosas preciosas con facultad del banquero para reivindicarlo de manos del adquirente, sin que existiera hipoteca.

4. Contratos de depósito bancario bajo la modalidad de no uso del dinero por parte del banquero, con la obligación de custodiar y restituir dicha suma, y la modalidad de depósito donde el banquero podía hacer uso de las sumas de dinero $^{8}$, práctica que se incorporó entre los siglos primero antes de Cristo y segundo después de Cristo (Cerami, 2017, p. 169). El depositario respondía por dolo, culpa lata y culpa leve si así se hubiera convenido. Igualmente, teniendo en cuenta que el depositario debía abstenerse de usar el dinero dado en depósito, este respondía en caso de haber obtenido ventaja del contrato. (Argüello, 1998, p. 314).

5. Antiphónesis, como garantía en la cual el banquero cumplía con una obligación de su cliente frente a su acreedor, en caso de iliquidez por parte del primero. Dicho contrato operaba como un mandato y, aunque no se exigía solemnidad, para probar la culminación del mandato (posterior al pago) era necesario

8 “El Derecho Romano conoció figuras especiales de depósito: el depósito necesario, el depósito regular y el secuestro [...]. El depósito irregular que tenía por objeto dinero u otras cosas fungibles que podía consumir el depositario, quien quedaba obligado a restituir otras tantas cosas del mismo género y calidad. Esta modalidad especial de depósito, que aplicaron generalmente los banqueros, no se diferenciaba esencialmente del mutuo" (Argüello, 1998, p. 315). 
demostrar por escrito su conclusión (Petrucci, 2010, p. 353).

6. Receptum argentarii era un pacto $^{9}$ mediante el cual los banqueros hacían una promesa de pago, es decir, acordaban con un cliente pagar la deuda que este tuviera con otro acreedor (Morineau e Iglesias, 2000, p. 194).

Bajo estos antecedentes, es preciso determinar las principales características del régimen legal romano de la actividad bancaria y su sistema de responsabilidad:

- La existencia de una jurisdicción especial en cabeza del praefectus urbi para conocer las causas pecuniarias de los banqueros, a través de un proceso de conocimiento extraordinario (cognitio extra ordinem), impuesto por Adriano en el siglo II d. C. Igualmente, el pretor podía ejercer control y represalias sobre los banqueros, por razón de sus conductas incorrectas o prohibidas. La finalidad de dichas acciones procesales era proteger al público en relación con las actividades negociales de los banqueros (Cerami, 2017, pp. 159-160).

- Una normatividad sustancial para la actividad bancaria desarrollada bajo los siguientes criterios: (1) edictos del pretor sobre exhibición de la contabilidad, garantía bancaria de pago, excepciones bancarias y compensación; (2) edictos del pretor e interpretación de los juristas sobre cuentas bancarias, quiebra de banqueros, obligaciones de pagar intereses, intermediación crediticia en las subastas; y (3) el régimen de solidaridad y representación de los banqueros (Cerami, 2017).

- Aplicación a los banqueros del régimen de responsabilidad contractual, común a los contratos de depósito irregular, el mandato de apertura de crédito y la stipulatio, entre otros (Cerami, 2017).

- La concesión que otorgó Justiniano a los banqueros en la Novela 136.3 sobre los bienes comprados por sus clientes con dinero prestados por ellos. En este supuesto, los banqueros prestaban dinero para la compra de bienes muebles o inmuebles

9 Los pactos eran una fuente adicional de las obligaciones en Roma. Se trata de acuerdos de voluntades desprovistos de forma (Morineau e Iglesias, 2000, p. 194). en el mercado, y la cantidad determinada se había dado y con lo prestado se había adquirido la cosa. Asimismo, los banqueros buscaban tener derecho de preferencia absoluta y no sufrir perjuicio, teniendo el comerciante la carga de probar que la cosa había sido comprada con dinero que habían prestado para tal fin. En este escenario, el banquero contaba con un privilegio igual al de la hipoteca, sin que se hubiese establecido de forma expresa una garantía de tal tipo (Díaz-Bautista, 1987, p. 61).

De allí, surge una verdadera discusión en relación con la naturaleza jurídica del contrato de mutuo, donde, al estar frente a una cosa fungible, el deudor se convierte en propietario del dinero, por lo que adquiría la obligación de reintegrar una suma de dinero, sumada a los correspondientes rendimientos. En caso de quiebra de los banqueros, debía priorizarse al pago de los depósitos entregados en relación con los otros créditos. Así, Ulpiano señala que

siempre que los banqueros se declaran en quiebra, se suele tener en cuenta, ante todo, a los depositantes, es decir, a los que tuvieron cantidades entregadas en depósito, y no prestadas con interés a los banqueros, juntamente con ellos o por mediación de ellos; por consiguiente si se hubieran vendido los bienes, se da preferencia a los depósitos sobre los créditos privilegiados, pero de modo que no se tengan en cuenta los que devengaron intereses, aunque sea, pues es como si se hubiera renunciado al depósito. Se pregunta asimismo si se atenderá a la prioridad de los depositantes o si se consideran todos los depósitos a la vez, y consta que han de ser admitidos simultáneamente pues así se expresa en un rescripto imperial. (Adame-Gorddard, 2013, p. 173)

A ello se suma un régimen de solidaridad activa y pasiva entre los banqueros socios en relación con terceros en materia contractual. En la práctica esta situación conlleva a que (1) "cada uno de los socios podía celebrar con terceros un negocio relacionado con la explotación del banco, adquiriendo derechos y obligaciones para los otros"; (2) "cada socio podía ser llamado por los terceros a responder por el entero en virtud de las actividades que hacían parte del objeto social"; y (3) "entre los banqueros socios 
las ganancias y las pérdidas del ejercicio del banco se distribuían según lo establecido en el contrato de sociedad, o en ausencia de dicho acuerdo, por partes iguales" (Cerami, 2017, p. 249).

\section{La banca en la Edad Media y su sistema de responsabilidad}

En la Edad Media, si bien no existía una banca en sentido estricto, existía una serie de actividades de la época, tales como créditos a corto y mediano plazo, anticipos, servicios de caja, emisión y descuentos de letras de cambio, órdenes de pago y cambios reales o especulativos, entre otros (Cassandro, 1999, p. 16). En ese sentido, además de cumplir cierto tipo de funciones públicas, como cambio de monedas y actividades fiscales, los banqueros desarrollaban actividades privadas, en concreto, depósitos regulares e irregulares y operaciones de crédito (Petrucci, 2010, p. 352).

Los banqueros se organizaron en corporaciones especiales, las cuales tenían sus propios estatutos y contaban con cierto tipo de prerrogativas, otorgadas dentro de la estructura de los fueros municipales, tales como una jurisdicción mercantil especial con procesos de conocimiento y ejecutivos ${ }^{10}$, más expeditos a favor de los comerciantes banqueros (Petrucci, 2010, p. 359).

En este punto, es necesario distinguir, por un lado, a los jueces que solo ejercían sus funciones en el término de duración de las ferias y, por otro, a los verdaderos tribunales en las plazas mercantiles. En la España del siglo XII, se creó el tribunal de la plaza mercantil de los "Reyes de Aragón, el cual se extendió más tarde por los dominios de la Corona de Castilla: en efecto, por el año de 1283 se erigió el consulado de comercio de Valencia; en 1343, el de Mallorca; en 1347, el de Barcelona; en 1388, el de Perpiñán; los de Burgos y Bilbao datan de 1494; el de Sevilla, de 1535; y el de Madrid, del año 1652" (López, 1843, p. 138).

10 En el caso español, existió la entrega de deudas a judíos como una forma de proceso ejecutivo especial recogido en el Cuaderno de las Cortes de Palencia de 1313 (Gribau-Coll, 2009, p. 582).
Las siete partidas con sus correspondientes comentarios determinaron sobre el particular, primero, en el Título VIII, se estableció que los tribunales comerciales deben juzgar verdad sabida y buena fe guardada, dejando de un lado las formalidades de Derecho, pero observando las leyes civiles y demás leyes; segundo, se estipuló que, ante el Tribunal, no puede solicitarse la pena más allá de lo que monta el perjuicio (López, 1843).

De igual manera, los fueros cumplieron un papel trascendental en el desarrollo de la actividad bancaria en la Edad Media. En consecuencia, frente a los fueros, los banqueros que ejercían la actividad de depósito tenían la obligación de (1) “jurar ejecutar fielmente los deberes propios y restituir sin dilación las sumas conservadas en depósito" y (2) "prestar garantías para el exacto cumplimiento de dichas obligaciones, consistentes en fiadores o en la posesión de un monto de patrimonio determinado" (Petrucci, 2010, p. 359).

Ahora bien, dentro de las principales operaciones bancarias que se materializaron durante la Edad Media se pueden traer a colación, los depósitos, el crédito y la letra de cambio.

Depósitos: igual que en el periodo romano, en la Edad Media se distinguían dos tipos de depósito bancario. En primer lugar, los cerrados, en los que el depositante podía disponer del dinero entregado al banquero para pagos en efectivo, sin que el banquero se convirtiera en propietario del dinero. En segundo lugar, los irregulares o abiertos, en los cuales el depositante recibía un rendimiento por el dinero y le permitía al banquero utilizarlo para operaciones de riesgo y empresa, haciendo partícipe al depositante en la empresa, y encubriéndose un contrato de mutuo con el pago de intereses (Argüello, 1998, p. 315).

Crédito: en la Edad Media, las operaciones crediticias eran calificadas de ilícitas, pues la Iglesia Católica consideraba que cualquier trato que generara interés traía como consecuencia la usura. Esta postura, además de fundamentarse en pasajes bíblicos, se relacionaba con la prohibición de que el dinero generara dinero, tomando como referente el proverbio: Nummus non parit nummus (Le Goff, 1984, p. 91). Siguiendo a Cassandro, el préstamo era ilícito según el Derecho Canónico "más allá 
de aquella tasa mínima que compensase al prestamista de la ausencia de beneficio (lucrum cessans) o que lo protegiese de las dificultades surgidas a causa de la indisponibilidad de la suma prestada (damnum emergens), según la interpretación de Tomás de Aquino y de la Escolástica”.

Lo anterior, fue una prohibición canónica que generaba una situación poco favorable para los bancos que, después, fue parcialmente abolida para algunos. Desde una perspectiva jurídica, se plantearon algunas excepciones sobre esta prohibición:

La existencia de un periculum sortis para el prestamista justificaba una remuneración, tal como era el caso del contrato de commenda o el contrato de sociedad; si la ejecución del contrato comportaba un daño emergente o un lucro cesante, se podía obtener una indemnización. El préstamo a interés fue autorizado, por último, a condición de que el prestamista fuera judío o lombardo. (Morles-Hernández, 2007, p. 611)

Por tal situación, los mercaderes banqueros ocultaban el pago de interés con operaciones tales como ventas diferidas, seguros, operaciones de cambio, entre otros. De igual manera, los mercaderes realizaban créditos a señores feudales, el clero y monarcas, entre otros, con el fin de obtener beneficios en materia comercial, concesiones y monopolios. (Cassandro, 1999, p. 21)

La letra de cambio. Los banqueros realizaban operaciones entre diferentes plazas, por medio de órdenes de pago con diferentes tipos de monedas que incluían operaciones ocultas de crédito y cobro de intereses. En este sentido, la letra de cambio fue el principal instrumento de intermediación de cambios en el mercado internacional. Ello permitió regular las operaciones de débito y crédito, pasando de simples permutaciones monetarias según su denominación originaria- a operar con créditos de mayor valor en el mercado cambiario de monedas (Cassandro, 1999, p. 24).

En este escenario, la letra de cambio tenía funciones como ser (1) medio de pago en operaciones comerciales; (2) medio de transferir fondos entre plazas que utilizaban monedas diferentes; (3) fuente de crédito; y (4) ganancia financiera al jugar con las diferencias y las variaciones de cambio en las diferentes plazas. En ese momento, no se conocían ni los endosos ni las operaciones de descuento (Le Goff, 1984, p. 37).

En el siglo xv europeo existió una separación entre la banca pública y la privada. La primera fue asumida por las municipalidades, debido a la quiebra de los bancos privados; mientras los fueros asumieron la prestación del servicio, estableciendo fuertes restricciones para evitar la insolvencia de los bancos. En cuanto a la banca privada, surgieron los grandes banqueros europeos en Italia y Alemania, con las familias Fugger ${ }^{11}$ y Welser ${ }^{12}$.

Así, la base primigenia de los grandes bancos privados surgió en Italia, inicialmente en Siena, y, tiempo después, en Génova, Estado donde, durante el siglo XII, se fundó el Banco de San Giorgio, que realizaba actividades como recibir depósitos sin interés y cambiar moneda ${ }^{13}$. Por otro lado,

11 Los Fugger eran una familia alemana de banqueros, "que adelantaron grandes sumas de dinero para que la elección de emperador recayera en Carlos de Gante (otros fueron los Welser, Grimaldi, Fornari y Centurione”. Como contrapartida, conseguirían "los arriendos de los mayorazgos de las órdenes militares, que incluían las minas de Almadén pertenecientes a la Orden de Alcántara” (Rizo-López, 2005, p. 225).

12 Los Welser eran una familia de banqueros de Augsburgo (Alemania), considerados una de las principales casas financieras de Europa en la primera mitad del siglo xvi (Polack, 1926, p. 2).

13 Entonces, nacieron y se concretaron distintas operaciones bancarias: “Depósitos a interés, préstamos, anticipos, giros, inversiones, así como, el perfeccionamiento de la contabilidad y el sistema de partida doble”. Después de experiencias negativas, "se aconsejó realizar la separación de las actividades financieras de las comerciales. Con dicha separación se obtuvieron grandes beneficios, a tal grado que la mayoría de esas prácticas son ejercidas en la actualidad [...]. Entre otras actividades están, la creación del Monte Vecchio por parte de acreedores de la República, dando origen a su documento de Deuda Pública, [...] se crearon los primeros bancos de depósito, a los que se les llamó ‘de giro’, ya que las operaciones que realizaban consistían en las transferencias entre cuentas. El comercio interno y externo se facilitó, ya que los bancos recibían metálico de los particulares, abriéndoles un crédito en registros que eran 
en Florencia, se crearon casas de préstamo pertenecientes a las poderosas familias Bardi, Peruzzi y Acciaioli, lo que potenció sus negocios en la banca. No obstante, entraron en crisis en 1339, al prestar altas sumas a monarcas europeos que, en ciertas oportunidades, eludían los pagos ${ }^{14}$.

Hasta la llegada de los Médicis, Florencia volvió a dominar la actividad bancaria. Posteriormente, empezaron a surgir nuevas leyes entorno a los préstamos que impedían a los bancos prestar a particulares cantidades que superaran los montos prestados al Estado, lo cual implicaba límites a los banqueros en su ejercicio profesional (León-Muri1lo, 2007, pp. 41-43). Igualmente, una de las funciones propias de la banca privada fue el depósito de dinero de particulares, asumiendo la responsabilidad en las situaciones de fraude y falsificaciones de moneda (Morales, 2016).

Desde el siglo xv hasta finales del siglo Xvin la banca estuvo ligada al comercio, los banqueros privados seguían realizando préstamos a la realeza, desarrollando influencia tanto económica como política. Entre ellos se destacan los ya mencionados Fugger, los Médicis y Jacques Coeur (León-Murillo, 2007, p. 43). A partir de los siglos XVIII y XIX, la banca privada estuvo afectada por dinámicas como las guerras napoleónicas ${ }^{15}$, que impactaron el comercio, la economía y la política ${ }^{16}$.

transmitidos de uno a otro particular, es decir, solo había anotaciones en los registros y ningún movimiento de monedas" (Unam, s.f.).

14 Un ejemplo de ello fue la falta de pago por parte del Parlamento británico y el rey de Sicilia, lo que llevó a las casas Bardi y Peruzzi a la bancarrota (El Mundo Financiero, 2019).

15 "Las guerras napoleónicas fueron financiadas con recursos provenientes de los territorios conquistados, pero la reconstrucción de los territorios corrió por cuenta del crédito aportado por casas bancarias extranjeras, en mayor medida por los bancos Barings y Hope” (Herrera-Valencia, 2017, p. 58).

16 "Las reconstrucciones y los periodos de guerra constituyeron un punto de inflexión, puesto que cambiaron los arreglos institucionales y la participación de los actores financieros involucrados, lo que se tradujo en la quiebra de varias compañías bancarias y comerciales, reduciendo la diná-
La transición producto de las guerras trajo consigo cambios importantes en el ámbito financiero. Ello terminó proyectando los créditos e instrumentos crediticios, dinamizando los mercados a nivel internacional y generando cambios en las instituciones y la función que desempeñaban los profesionales de la banca e intermediarios financieros, principalmente, en los países europeos. En este contexto, surgieron las capitales financieras más importantes: Londres, París y Ámsterdam ${ }^{17}$; seguidos de Inglaterra que, en el siglo xIx, lideró tanto la producción y exportación de manufacturas, como la actividad bancaria del mundo occidental, lo que la convirtió en una potencia comercial (Herrera-Valencia, 2017).

\section{Reflexiones sobre}

\section{la consagración de la responsabilidad civil bancaria en algunas codificaciones y su desarrollo en Colombia}

Dentro de los procesos de codificación, en la Francia napoleónica se creó el Banco de Francia ${ }^{18}$ (des Essars, 1896, p. 56), con un fuerte contenido de carácter monopólico, y se estableció el Código de Comercio, que reguló algunos temas sobre banca. $\mathrm{Al}$ respecto, es necesario traer a colación que, en el caso francés, el régimen de responsabilidad bancaria se desarrolló con el régimen de la culpa, en

mica financiera en estas capitales [...]. Cabe resaltar que en opinión de Cassis, los bancos privados fueron definidos más por su tipo de propiedad que por sus actividades” (Herrera-Valencia, 2017, p. 52).

17 "La particularidad del Banco de Ámsterdam era la de haber servido como institución que vigilaba el valor del dinero-mercancía, y en ese sentido funcionaba como el primer banco central moderno" (Herrera-Valencia, 2017, p. 54).

18 Las principales operaciones del Banco de Francia eran descontar letras de cambio; realizar cobros por cuenta de ciudadanos y establecimientos públicos; recibir depósitos y pagar cheques; emitir notas al portador pagaderos a la vista; y abrir un Departamento de Inversión y Ahorro (des Essars, 1896, p. 56). 
los términos de los artículos $1382^{[19]}, 1386-16^{[20]} \mathrm{y}$ concordantes del Código Civil francés. En cuanto a operaciones de crédito, el régimen de responsabilidad fue producto de desarrollo jurisprudencial, plasmado en la Ley del 26 de julio de 2005 (Rodríguez-González, 2011, p. 441).

Como se dijo, el sistema de responsabilidad se estructuró a partir de la culpa, en varios supuestos: (1) el rechazo del crédito; (2) la negativa a continuar la relación crediticia; (3) la concesión de un crédito ruinoso; y (4) el sostenimiento abusivo de la relación crediticia. Sumado a estos supuestos, la Ley 2005-845 de 2005 estableció un régimen de responsabilidad para los bancos en caso de los deudores en procesos de insolvencia, al determinar un verdadero régimen de irresponsabilidad con algunos tipos de excepciones: "Los acreedores no podrán ser considerados responsables de los perjuicios que se deriven de las ayudas otorgadas, salvo en caso de fraude, intromisión en la gestión del deudor, o si las garantías suscritas como contrapartida de estas ayudas fueran desproporcionados con relación a estos" (Código de Comercio de Francia, art. L. 650-1).

En el caso italiano, el régimen de responsabilidad de las instituciones financieras se fundamenta también en la culpa. A título de ejemplo, el artículo 1836 del Codice Civile establece: "Se il libretto di deposito è pagabile al portatore, la banca che senza dolo o colpa grave adempie la prestazione nei confronti del possessore è liberata, anche se questi non è il depositante"21 (énfasis agregado).

19 "Cualquier hecho de la persona que cause a otra un daño, obligará a aquella por cuya culpa se causó, a repararlo (Código Civil de Francia, art. 1382).

20 Artículo 1386-16 del Código Civil de Francia, introducido por la Ley 98-389 de 19 de mayo de 1998 art. 1 y art. 18, señala: "Salvo culpa del productor, su responsabilidad, fundada en las disposiciones del presente título, se extinguirá diez años después de la puesta en circulación del producto que hubiera causado el daño a no ser que, durante este periodo, la víctima hubiera emprendido una acción legal".

21 Ver el Codice Civile (edición 2020) en https://www. studiocataldi.it/codicecivile/codice-civile.pdf.
En España el régimen de responsabilidad civil de las instituciones bancarias se justifica también en la culpa, establecido en los términos de los artículos $1089^{[22]}, 1093^{[23]}, 1104^{[24]}$ y $1902^{[25]}$ del Código Civil español ${ }^{26}$.

En Colombia, el desarrollo legislativo sobre el régimen de responsabilidad civil de las instituciones financieras tiene como antecedente la Ley 46 de 1923:

Todo banco será responsable a un depositante por el pago, que aquél haga de un cheque falso o cuya cantidad se haya aumentado, salvo que dicho depositante no notifique al banco, dentro de un año después de que se le devuelva el comprobante de tal pago, que

22 "Las obligaciones nacen de la ley, de los contratos y cuasi contratos, y de los actos y omisiones ilícitos o en que intervenga cualquier género de culpa o negligencia” (Código Civil español, art. 1089).

23 "Las que se deriven de actos u omisiones en que intervenga culpa o negligencia no penadas por la ley, quedarán sometidas a las disposiciones del capítulo II del título XVI de este libro” (Código Civil español, art. 1093).

24 "La culpa o negligencia del deudor consiste en la omisión de aquella diligencia que exija la naturaleza de la obligación y corresponda a las circunstancias de las personas, del tiempo y del lugar. Cuando la obligación no exprese la diligencia que ha de prestarse en su cumplimiento, se exigirá la que correspondería a un buen padre de familia” (Código Civil español, art. 1104)

25 “El que por acción u omisión causa daño a otro, interviniendo culpa o negligencia, está obligado a reparar el daño causado” (Código Civil español, art. 1902).

26 El Tribunal Supremo Español ha desarrollado una serie de sentencias en relación con el régimen de responsabilidad de los bancos por las personas. El tribunal “consideró que en todos los casos similares en que había considerado a los bancos responsables por los actos de sus empleados, que con su conducta ocasionaron daños a sus propios clientes, había sido debido a que el banco no había cumplido 'lo que el art. 6:102 [sic: rectius 6:101] de los Principios de Derecho Europeo de Responsabilidad civil, denomina el estándar de conducta que le era exigible en la supervisión' (to the required standard of conduct in supervision) o lo que es lo mismo, se había infringido el deber de vigilancia” (Casadella-Sánchez, 2014, p. 92). 
el cheque así pagado era falso o que la cantidad de él se había aumentado. (art. 191)

Por otra parte, el artículo 1604 del Código Civil colombiano establece el régimen de responsabilidad contractual basado en la culpa, motivo por el cual, la culpa es un elemento eximente de responsabilidad. Bajo este presupuesto, podría determinarse, en primera medida, que el régimen de responsabilidad civil contractual aplicable a las instituciones financieras sería el establecido en el citado artículo 1604, aunque el tema no ha sido nada pacífico.

Siguiendo la investigación de Padilla y Zafra (2017), observamos que la legislación colombiana ha evolucionado desde la Ley 46 de 1923, la cual establecía la responsabilidad de los bancos en torno a la indemnización por los perjuicios económicos causados a los clientes, oscilando así entre los regímenes de responsabilidad objetivo y subjetivo. Sin embargo, no se establecía con exactitud un régimen de responsabilidad. En palabras de Rodríguez-Zárate (2014), "el límite entre el régimen de responsabilidad contractual bajo la culpa presunta descrita en el artículo 1604 del Código Civil y el régimen de responsabilidad extracontractual objetivo y bajo la teoría del riesgo, es difuso" (p. 298). Bajo estos presupuestos, enseguida, se analiza el desarrollo de la teoría de la responsabilidad objetiva en materia de bancaria en Colombia.

\section{La posibilidad de hablar de un régimen especial de responsabilidad civil de las instituciones financieras en Colombia}

En materia bancaria debería existir un sistema de responsabilidad civil especial que favorezca los intereses de los consumidores financieros, al ser la parte débil de la relación contractual. Dicho régimen puede ser un sistema objetivo de responsabilidad, una presunción de culpa - como ocurre en el caso colombiano- o el uso de remedios procesales como la carga dinámica de la prueba ${ }^{27}$.

27 "Se ha reconocido en la mayoría de los estatutos del consumidor un criterio de aplicación de responsabilidad objetiva en las relaciones de consumo, al igual que el reconocimiento de forma excepcional del régimen de riesgo creado en materia
En efecto, la confianza en los bancos es esencial para la configuración de un mercado financiero sólido, como ha manifestado la Corte Suprema de Justicia, al señalar que el mercado financiero es una actividad de interés público, que debe ser realizada por profesionales en la materia, con altos estándares de diligencia y con una alta carga de especial atención y cuidado,

pues, en materia tan delicada, no hay espacio para tolerar desbordamientos, abusos o descuidos, que amén de poner en peligro la estabilidad económica de la institución misma y de la nación toda, tienen la potencialidad de resquebrajar la confianza pública en un servicio en el que, se itera, existe un interés general. (Corte Suprema de Justicia de Colombia, Sala de Casación Civil, Sentencia 7447, 2004)

Asimismo, la relación entre instituciones financieras y consumidor debe orientarse a la satisfacción de las necesidades de los usuarios, para promover su confianza en el mercado bancario. Por lo anterior, la Constitución ${ }^{28}$ consagra la protección al consumidor para evitar asimetrías de información, poniendo a su disposición mecanismos adecuados para adquirir los bienes y servicios, a través de una información clara y precisa que cumpla con los estándares de seguridad y calidad. Igualmente, el artículo 3 de la Ley 1328 de

bancaria, se pone de presente la importancia de establecer un régimen de responsabilidad objetiva que se aplique a todas las relaciones que se materialicen entre los consumidores y las instituciones financieras. Otra posible solución sería el uso de mecanismos de inversión de carga de la prueba que facilite la obligación procesal del consumidor” (Corredor-Higuera, 2015, p. 960).

28 "La ley regulará el control de calidad de bienes y servicios ofrecidos y prestados a la comunidad, así como la información que debe suministrarse al público en su comercialización. Serán responsables, de acuerdo con la ley, quienes en la producción y en la comercialización de bienes y servicios, atenten contra la salud, la seguridad y el adecuado aprovisionamiento a consumidores y usuarios [...]. El Estado garantizará la participación de las organizaciones de consumidores y usuarios en el estudio de las disposiciones que les conciernen” (Constitución Política de Colombia [Const.], art. 78). 
2009 define los principios que trazan la filosofía de la actividad financiera, como la debida diligencia, la transparencia, la información cierta, suficiente y oportuna, la responsabilidad en el trámite de requerimientos de los consumidores y la educación al consumidor financieros, entre otros. Estos principios promueven la protección al equilibrio en las relaciones y evitan la estipulación de cláusulas abusivas.

Desde estos presupuestos, se realiza un breve análisis jurisprudencial de la responsabilidad civil bancaria en Colombia, partiendo del desarrollo jurisprudencial por parte de la Delegatura para Funciones Jurisdiccionales de la Superintendencia Financiera de Colombia ${ }^{29}$ y de la Sala de Casación Civil de la Corte Suprema de Justicia.

La Delegatura para Funciones Jurisdiccionales de la Superintendencia Financiera de Colombia ha establecido la existencia de un régimen especial de responsabilidad dentro de la actividad bancaria, que se exalta bajo los estandartes de debida diligencia y profesionalismo que se exige a los bancos. Es así como, en escenarios de discusión contractual respecto a quién cabe la responsabilidad de transacciones fraudulentas sobre depósitos de ahorro, la delegatura ha enunciado lo prescrito por el artículo 1398 del Código de Comercio ${ }^{30}$, como soporte de una responsabilidad que se endilgaría al establecimiento de crédito que incumpla la obligación a su cargo de entregar las sumas depositadas al titular de la cuenta, su mandatario o a la persona que el cuentahabiente autorice, sin que pueda aceptarse prueba de diligencia como eximente de responsabilidad.

Adicionalmente, la delegatura ha reiterado la obligación que compete a las entidades financieras de ofrecer productos y servicios que cumplan con

29 En Colombia, la Constitución otorga funciones jurisdiccionales a las entidades administrativas, a través de una ley específica, para temas puntuales civiles y comerciales y con respeto de la autonomía de la función judicial. Sobre el particular ver Corredor (2016).

30 "Todo banco es responsable por el reembolso de sumas depositadas que haga a persona distinta del titular de la cuenta o de su mandatario" (Código de Comercio colombiano, art. 1398). estándares de seguridad y calidad para no generar perjuicios a los consumidores ${ }^{31}$. Entonces, como señalan Padilla y Zafra (2017), el criterio de seguridad tiene una gran incidencia para determinar la responsabilidad bancaria.

A pesar de los parámetros de responsabilidad exigidos a las entidades financieras, basados en el deber de comportamiento profesionales según su especialidad y experticia, en virtud del riesgo creado inherente al desarrollo de sus actividades financieras, también es importante considerar que la atribución de responsabilidad no recae de manera absoluta sobre las entidades financieras. Ello se fundamenta en que, en casos específicos, incluso, debe evaluarse el cumplimiento de los deberes de prudencia y diligencia del consumidor financiero, para identificar el grado de responsabilidad de la entidad financiera o si hay lugar a la exoneración total o parcial de ella (Paz-Sefair, 2018).

Lo anterior ha sido confirmado en el estudio jurisdiccional de la Superintendencia Financiera sobre asuntos contenciosos, en materia de contratos de depósito de ahorro. También está en la base de las disquisiciones fácticas que se siguen en cada caso y se ha extendido a los contratos de depósito de cuenta corriente y apertura de crédito (Corredor y Paz, 2016, p. 185).

La jurisprudencia de la Corte Suprema de Justicia $^{32}$ desde 1936 estableció que, a las entida-

31 "Los consumidores financieros tienen durante todos los momentos de su relación con la entidad vigilada, el derecho de recibir de parte de las entidades productos y servicios con estándares de seguridad y calidad, de acuerdo con las condiciones ofrecidas y las obligaciones asumidas por las entidades vigiladas [...]. En igual sentido, el literal f del artículo 5 ibídem indica que aquellos derechos que se encuentren inmersos en la ley o en las instrucciones impartidas por esta superintendencia, cobijarán las relaciones existentes entre los consumidores financieros y las entidades vigiladas, por lo que, ante la existencia de un contrato entre estos, en el mismo se entienden incorporados los derechos consagrados en tales disposiciones normativas" (Superintendencia Financiera de Colombia, Delegatura para Funciones Jurisdiccionales, Sentencia 069, 2013).

32 Sentencias de Sala de Casación Civil de la Corte Su- 
des financieras, se podría aplicarles el régimen de responsabilidad objetiva con fundamento en la teoría del riesgo creado ${ }^{33}$. Así, esa Corte determinó que el artículo 191 de la Ley 46 de 1923 "por su contexto consagra el sistema del riesgo creado: es decir, el aludido principio de que la responsabilidad por el pago de un cheque falso es el riesgo normal del comercio de banco" (Corte Suprema de Justicia, Sentencia del 09 de diciembre,1936).

Posteriormente, con la entrada en vigor del Código de Comercio (1971), la Corte retomó en sus providencias la teoría del riesgo creado y el riesgo beneficio ${ }^{34}$, para fundamentar el régimen de responsabilidad objetiva aplicable a las entidades bancarias. Con base en el artículo 1391 del Código de Comercio, estableció que la atribución de responsabilidad del banco deriva del riesgo inherente a la actividad financiera.

Sobre el particular, la Sala de Casación Civil de la Corte Suprema de Justicia determinó que la obligación del banco de resarcir los perjuicios ocasionados al cuentacorrentista con el pago de cheques falsos surgía, del "principio de responsabilidad de empresa”, en virtud del cual es la entidad que desarolla la actividad empresarial a la que corresponde asumir las contingencias o riesgos que acarrea su operación. Entre esos riesgos está el pago de cheques cuya falsificación no pueda imputarse al librador, no solo por cuanto son inherentes a aquélla, sino porque se trata de una actividad realizada bajo su control, y de la cual obtiene beneficio. Por ello, no se exige al cliente demostrar la culpa de la entidad (Sentencia SC18614-2016, 2016).

Igualmente, la misma Corte estipuló que el régimen de responsabilidad de las entidades

prema de Justicia: Sentencia del 9 de diciembre de 1936 y Sentencia del 15 de julio de 1938.

33 "En el escenario del riesgo creado, quien en desarrollo de una actividad genere un riesgo está en la obligación de indemnizar los perjuicios que de este devengan sobre terceros" (Rodríguez-Zárate, 2014, p. 295).

34 Generado por alguien que ejerza una actividad riesgosa y obtenga una utilidad de ello, quien, a su vez, debe indemnizar por los perjuicios causados, independientemente de si actúo de forma diligente o no. financieras es el de la responsabilidad objetiva, cambiando la perspectiva de la teoría del riesgo, ahora desde la óptica del grado máximo de diligencia que deben tener los profesionales que se desempeñan en las actividades bancarias. Así, la Sala de Casación Civil estableció una inversión de la carga de la prueba a favor del consumidor financiero, tratándose del reembolso de la suma de dinero depositadas en depósitos bancarios de cuenta corriente o de cuenta de ahorro ${ }^{35}$.

Otra discusión gira en torno a lo relacionado con el régimen de responsabilidad de las instituciones bancarias, por fraudes electrónicos realizados por terceros, que afectan los recursos de los consumidores financieros ${ }^{36}$. Se considera aquí que la institución financiera al obtener un provecho económico del uso de instrumentos electrónicos,

35 La Corte determinó que tal circunstancia "no conlleva la inaplicabilidad del régimen de responsabilidad reconocido por ellas a otra clase de defraudaciones cometidas tanto en la disposición irregular de recursos pecuniarios en cuentas corrientes como en las de ahorro, pues lo que subyace en la regulación mencionada es que el ordenamiento positivo reconoce que las instituciones bancarias ejercen una actividad que es profesional, habitual y de la que deriva un provecho económico, a la que le es inherente una multiplicidad de peligros [...], que pueden afectar los intereses de los cuentahabientes por la mala disposición de sus depósitos [...]. Claro está, sin desconocer, en ninguno de los dos casos, que la responsabilidad de dicha institución financiera puede atenuarse, moderarse e incluso excluirse" (Corte Suprema de Justicia, Sala de Casación Civil, Sentencia SC18614-2016, 2016).

36 Dentro de los principales fraudes electrónicos bancarios se encuentran: "Phishing: consiste en el envío de correos electrónicos fraudulentos que dirigen a los clientes a páginas web falsas que aparentan ser de la entidad bancaria [...]. Vishing: se refiere al tipo de amenaza que combina una llamada telefónica fraudulenta con información obtenida desde Internet. Smishing: así como las llamadas telefónicas son una vía para tratar de engañar a los clientes, también lo son los mensajes de texto o mensajes por WhatsApp; de ahí deriva la modalidad conocida como smishing" (Castillo, 2019). 
especialmente en lo relacionado con canales de pago, y al generar un potencial riesgos por dicha situación frente a los consumidores financieros, debe contar con un régimen de responsabilidad especial, fuera de los lineamientos generales de la responsabilidad civil basada en la culpa probada.

Este postulado fue desarrollado en Colombia por la Sala Civil de la Corte Suprema de Justicia (Sentencia SC18614-2016 de, 2016), la cual determinó que, en materia de fraudes electrónicos, debe aplicarse a la institución bancaria un régimen de responsabilidad civil especial ${ }^{37}$.

Con respecto a la responsabilidad y su incidencia en el uso de medios electrónicos de pago, la Corte Suprema de Justicia ha analizado la teoría de "exposición al peligro", entendida no solo desde la óptica del riesgo creado (por el desarrollo de la actividad bancaria) y el riesgo provecho, sino también por la intervención de un tercero a las operaciones ${ }^{38}$.

37 "Atendiendo la naturaleza de la actividad [...], el interés público que en ella existe; el profesionalismo exigido a la entidad y el provecho que de sus operaciones obtiene, los riesgos de pérdida por transacciones electrónicas corren por su cuenta, y por tanto, deben asumir las consecuencias derivadas de la materialización de esos riesgos a través de reparar los perjuicios causados [...]. Desde luego que, consumada la defraudación, el banco para exonerarse de responsabilidad debe probar que esta ocurrió por culpa del cuentahabiente o de sus dependientes[...], pues amén de que es este quien tiene el control de mecanismo que le permiten hacer seguimiento informático a las operaciones a través de controles implantados en los softwares especializados con los que cuentan, la culpa incumbe demostrarla a quien la alegue (art. 835 Const.)" (Corte Suprema de Justicia, Sala de Casación Civil Sentencia SC18614-2016, 2016).

38 Según Anaya (2012), "aquel que introduce un riesgo en razón a la actividad que realiza, no siempre se hace objeto de la aplicación de la teoría del riesgo provecho o empresa, porque no en todos los casos es facultad de quien se beneficia del riesgo el prevenirlo o controlarlo, pues puede tratarse de una persona no profesional en el campo, o que no tiene el carácter de empresario [...], sin embargo, se aprovecha de la actividad que realiza y del riesgo que provoca".
De la citada sentencia, se concluye que existe una inversión de la carga de la prueba a favor del consumidor financiero, motivo por el cual, cabe la posibilidad, para el banco, de exonerarse de responsabilidad, probando la culpa del consumidor financiero dentro de la materialización del fraude electrónico. No obstante, la entidad bancaría requeriría la implementación de mecanismos de autenticación más eficientes para evitar el fraude y, aun así, no tendría ningún control sobre la conducta de cuidado que debe asumir el consumidor (Rodríguez-Bonil, 2017, p. 76). Igualmente, la negligencia y omisiones propias del consumidor son conductas difíciles de probar, por lo que podría incluso salir más oneroso agotar un proceso probatorio que resarcir los daños demandados.

Por lo anterior, en lo referente a dicha discusión, es oportuno revisar el marco de la responsabilidad desde una óptica en la que, a pesar de estar informado, el consumidor financiero omite con su conducta determinados estándares de seguridad que impiden que la entidad financiera proteja al usuario de soportar determinados perjuicios.

\section{Conclusiones}

La actividad bancaria ha evolucionado, haciendo más notoria la transversalidad entre el sistema bancario y las dinámicas sociales, económicas y culturales. El desarrollo de la industria bancaria puede comprenderse desde las primeras actividades, como el comercio de metales preciosos y otras mercancías; el depósito en custodia administrados por templos, palacios y, posteriormente, banqueros privados que, con el intercambio comercial, se declararon cambistas, entre otras actividades. Enseguida, durante la edad moderna se estructuraron los primeros bancos y surgieron, como principales actividades bancarias, las operaciones de crédito. Ello ha facilitado la circulación de monedas en el mercado hasta la actualidad.

Estos procesos, condicionados al desarrollo económico de cada época, evidencian los disímiles retos de la regulación frente al diseño de mecanismos óptimos para la gestión de riesgos y atribución de responsabilidad, con el objetivo de mantener la 
confianza de los consumidores en las entidades bancarias.

Desde épocas remotas, la banca ha sido un soporte para el crecimiento económico y social. Bajo este postulado, los diferentes sistemas jurídicos han asignado un régimen de responsabilidad que responde al desarrollo de dicha institución; desde la prohibición de ciertas actividades bancarias, pasando por la fuerte intervención económica, el sistema de las penas privadas y públicas, el régimen de responsabilidad por culpa, hasta llegar a sistemas especiales de responsabilidad dentro de las relaciones de consumo entre instituciones financieras y consumidores.

Sobre el último punto, puede concluirse que, en el caso colombiano, los desarrollos jurisprudenciales establecieron en sistema de presunción de culpa en contra de las instituciones bancarias. Dentro de tal sistema, este tipo de instituciones pueden ser exoneradas si prueban la culpa del consumidor. Así, hasta la fecha no se ha establecido un sistema de responsabilidad objetiva frente a la actividad bancaria, donde la única forma de exonerarse de responsabilidad es demostrando la causa extraña. No obstante, el desarrollo de este tipo de responsabilidad no se ha extendido a todas las jurisdicciones, motivo por el cual, se espera que en un futuro cercano se materialice procesos legislativos y jurisprudenciales que establezcan un verdadero régimen de responsabilidad especial frente a las instituciones financieras.

\section{Referencias}

Adame-Gorddard, J. (2013). Cuatrocientos casos y respuestas de los juristas romanos. Unam.

Anaya-Saade, C. (2012). Riesgos en las transacciones electrónicas bancarias. Una carga que debe ser asumida por la banca. Revista E-mercatoria, 11(1), 287-331.

Andreu, J. (1999). Banking and Business in the Roman World. Cambridge University Press.

Argüello, L. R. (1998). Manual de Derecho Romano. Historia e instituciones. Astreda.

Cabrera-Peña, K. (2011). El derecho del consumo: desde la teoría clásica del contrato hasta los nuevos contratos. Revista de Derecho, 35, 55-95.

Casadella-Sánchez, M. (2014). La responsabilidad civil del principal por hecho de sus auxiliares. En especial, la re- lación de dependencia (Tesis doctoral, Universitat de Girona). Repositorio institucional Universitat de Girona https://bit.ly/3eIer9w

Cassandro, M. (1999). Crédito, banca e instrumentos de pago en la Italia medieval. Edad Media, 2, 13-34.

Castillo, C. (2019, 25 de abril). 'Phishing', 'vishing', 'smishing', ¿qué son y cómo protegerse de estas amenazas? https:/www.bbva.com/es/phishing-vishing-smishing-que-son-y-como-protegerse-de-estas-amenazas/

Cerami, P. (2017). Derecho comercial romano. Perspectiva histórica. Universidad Externado de Colombia.

Código de Comercio de Francia [M. M. Carrón, Trad.] (s.f.).

Código de Hammurabi (s.f.). Luarna. Disponible en https://bit.ly/33ACyk6

Corredor-Higuera, J. (2015). La armonización en materia de protección al consumidor financiero en América Latina. Boletín Mexicano de derecho comparado, 48(144), 931-972.

Corredor-Higuera, J. y Paz-Sefair, A. (2016). Reflexiones sobre las funciones jurisdiccionales de la Superintendencia Financiera de Colombia. Entramado, 12(1), 174-200. https://doi.org/10.18041/entramado.2016v12n1.23119

Corte Suprema de Justicia, Sala de Casación Civil (1936, 09 de diciembre). Sentencia del 09 de diciembre [MP Antonio Rocha].

Corte Suprema de Justicia de Colombia, Sala de Casación Civil (2004, 03 de agosto). Sentencia 7447 [MP Edgardo Villamil Portilla]. https://bit.ly/2SAROv1

Corte Suprema de Justicia, Sala de Casación Civil (2016, 19 de diciembre). Sentencia SC18614-2016 [MP Ariel Salazar Ramírez]. https://bit.ly/3flcA9H

Del Granado, J. (2009). La genialidad del Derecho Romano, una perspectiva desde el análisis económico del derecho. Revista do Ministério Público do RS, 36 169-195.

Des Essars, P. (1896). A History of Banking in the Latin Nation. Vol. III. The Journal of Commerce and Commercial Bulletin.

Díaz-Bautista, A. (1987). Estudios sobre la banca bizantina: negocios bancarios en la legislación de Justiniano. Universidad de Murcia.

Duarte-French, J. (1959, 20 de enero). Notas editoriales. Revista del Banco de la República, 4-31. https://bit.ly/ 3tH1FfN

El Mundo Financiero (2019 14 de enero). ¿Cómo nacieron los bancos? https://www.elmundofinanciero.com/no- 
ticia/79653/economia/el-primer-banco-de-la-historia. html

Quisbert, E. (2006). Las XII tablas. Autor. Disponible en http://ermoquisbert.tripod.com/dr/12t/12t_apunte. pdf

Esmonde-Cleary, S. (2000). The Ending of Roman Britain. Routledge.

Fernández S. C., Fernández, J. y Fernández, C. (2000). Breves antecedentes históricos de la usura. En C. Fernández, J. Hernández y C. Fernández, El contrato de préstamo y crédito. Jurisprudencia y doctrina española (Tomo II, pp. 385-348). Ediciones Jurídicas Dijusa.

Gallo, R. (2013). Grecia y Roma. Algunas cuestiones sobre derecho mercantil y penal a través de su historia. Dunken.

García-Ludeña, M. (2015). La responsabilidad de los inversores financieros en Roma obligados entre sí por un contrato de sociedad. Revista de Derecho Uned, 17, 775-812.

Gribau-Coll, A. (2009). El juicio ejecutivo: perspectiva histórica desde el prisma del título ejecutivo. En M. Serra-Domínguez, Realismo Jurídico y experiencia procesal (pp. 571-638) Atelier Libros Jurídicos.

Herrera-Valencia, B. (2017). Globalización financiera: banca, regulación y crisis. Universidad Externado de Colombia.

Jursa, M. (2002). Debts and Indebtedness in the Neo-Babylonian Period: Evidence from the Institutional Archives. En M. Hudson y M. Van De Mieroop (Eds.). Debt and Economic Renewal in the Ancient Near East (pp. 197-223). Bethesda.

Le Goff, J. (1984). Mercaderes y banqueros de la Edad Media. Editorial Universitaria de Buenos Aires.

León-Murillo, A. (2007). Naturaleza jurídica del crédito sindicado (Tesis de grado, Universidad de Costa Rica). Repositorio institucional UCR http://repositorio.sibdi. ucr.ac.cr:8080/xmlui/handle/123456789/1429

López-López, M. (2003). Interpretatio nominum y diversificación del concepto de ratio en Plauto. Revista de estudios latinos, 3, 29-44.

López, G. (1843). Las siete partidas del Rey Alfonso el IX. Tomo III. Imprenta de Antonio Bergnes. Disponible en http://fama2.us.es/fde/ocr/2006/sietePartidasT5.pdf

Marcos-Celestino, M. (2000). La Ley de las XII tablas. Helmantica, 51(155), 353-383.

Martínez, C. y Rojas, S. (2018). Sin dolo y sin culpa: un nuevo paradigma jurisprudencial para la responsabilidad bancaria. Foro de Derecho Mercantil, No. 60. Legis. Disponible en https://bit.ly/3faGQnS
Morales, J. (2016, 12 de diciembre). Historia de la banca $y$ de los Bancos Centrales. https://www.conacento.info/ index.php/2016/12/12/historia-de-la-banca-y-de-losbancos-centrales/

Morineau, M. e Iglesias, R. (2000). Derecho Romano. Oxford University Press.

Morles-Hernández, A. (2007). Curso de Derecho Mercantil. Tomo I. Introducción. La empresa. El empresario. Universidad Católica Andrés Bello.

Murillo-Villar, A. (2014). La responsabilidad del banquero por los depósitos de los clientes. Una reflexión desde las fuentes romanas. Rivista di Diritto Romano 14, 1-10. https://bit.ly/2ROyeuO

Padilla, J. A. y Zafra, M. (2017). Responsabilidad de los establecimientos bancarios por el pago de cheques falsos o alterados en Colombia. Revista de Derecho Privado, 32, 383- 420 .

Paz-Sefair, A. (2018). La culpa del consumidor en la responsabilidad financiera y su proyección causal en el daño por fraude electrónico. Revista de Derecho Privado, 35, 261-289.

Pérez-Ramírez, J. (2009). Banco y contabilidad. Historias, instituciones, riesgos y normas internacionales IFRS. Marcial Pons.

Petrucci, A. (2010). Los bancos y las actividades bancarias en el medioevo e inicios de la edad moderna (Siglo XX$X V I I)$. Universidad Panamericana. Facultad de Derecho.

Polack, W. G. (1926). The Building of a Great Church: A Brief History of Our Lutheran Church in America. Concordia.

Rizo-López, A. (2005). Apuntes sobre la Comunidad Gitana Española: Breves Trazos de su Historia en Conexión con el Contexto Europeo. Diálogos Revista Electrónica de Historia, 6(1), 179-229.

Rodríguez-Bonil, M. (2017). Critica al esquema de responsabilidad bancaria, frente a los incentivos de adopción de medidas de uso seguro de medios electrónicos por los consumidores financieros (Tesis de grado, Universidad Externado de Colombia).

Rodríguez-González, M. (2011). La responsabilidad bancaria derivada de las operaciones de crédito en el derecho francés. Revista de Derecho Privado, 20, 437-454.

Rodríguez-Zárate, A. (2014). Análisis económico de la responsabilidad bancaria frente a los fraudes electrónicos: el riesgo provecho, el riesgo creado y el riesgo profesional. Vniversitas, 63(128), 285-314. https://doi. org/10.11144/Javeriana.VJ128.aerb

Salazar-Revuelta, M. (2013). El deber de información, transparencia y responsabilidad ante los depósitos de 
los clientes por parte de la banca: precedentes romanos. Revista Internacional de Derecho Romano, 11, 88149.

Schmitz, L. (1875). Mensarii. En J. Murray (Ed.), A dictionary of Greek and Roman antiquities [Diccionario de antigüedades griegas y romanas]. Universidad de Chicago. Disponible en http://penelope.uchicago.edu/ Thayer/E/Roman/Texts/secondary/SMIGRA*/Mensarii.html

Schmitz, L. (1875). Argentarii. En J. Murray (Ed.), A dictionary of Greek and Roman antiquities [Diccionario de antigüedades griegas y romanas]. Universidad de Chicago. Disponible en http://penelope.uchicago.edu/ Thayer/E/Roman/Texts/secondary/SMIGRA*/Argentarii.html
Soriano-Cienfuegos, C. (2010). Una mirada al mundo financiero de la antigüedad a través de las funciones bancarias de la Roma empresarial. Facultad de Derecho Universidad Panamericana.

Superintendencia Financiera de Colombia, Delegatura para Funciones Jurisdiccionales (2013, 24 de enero). Sentencia 069 de 24 de enero de 2014. https://bit.ly/ 3vT809s

Universidad Nacional Autónoma de México -Unam. (s.f.). Breve reseña histórica del surgimiento de la banca. Autor.

Villamarín-Gutiérrez, H. (1972). Evolución del Derecho bancario. Estudio general y legislación colombiana. Contraloría General de Boyacá. 